\title{
Qualidade da Água para Consumo Humano na Cidade do Uíge (Angola): Água Tratada do Sistema de Abastecimento Público e Água não Tratada de Fontes Alternativas
}

\author{
Paulo Manuel ${ }^{1}$ \\ Anabela A. Leitão ${ }^{2}$ \\ Rui A.R. Boaventura ${ }^{3}$ \\ ${ }^{1}$ Instituto Superior de Ciências da Educação (ISCED) do Uíge, Angola; E-Mail: paulomanuelelsa@yahoo.com.br \\ ${ }^{2}$ Universidade Agostinho Neto, Angola; E-Mail: anabela.leitao@yahoo.com \\ ${ }^{3}$ Universidade do Porto, Portugal; E-Mail: bventura@fe.up.pt
}

\section{Resumo}

Estima-se que cerca de $85 \%$ das doenças nos países em desenvolvimento são de veiculação hídrica e devem-se maioritariamente ao consumo de água de má qualidade. Neste trabalho avaliou-se a qualidade físico-química e microbiológica da água consumida pela população da cidade do Uíge. Foram realizadas quatro campanhas de amostragem em 10 pontos do sistema de abastecimento público, em três furos e nove cacimbas, e foram analisados 21 parâmetros físico-químicos e dois microbiológicos. Os resultados mostram que a água, à saída dos sistemas de tratamento, se pode considerar de boa qualidade apenas na ETA nova, sendo a proveniente de torneiras e furos artesianos própria para consumo em termos físico-químicos mas imprópria do ponto de vista microbiológico. A água das cacimbas é de muito má qualidade. Foi detetada contaminação bacteriológica em cerca de $58 \%$ das amostras de água das torneiras, em mais de $80 \%$ das amostras dos furos e em quase $100 \%$ das amostras das cacimbas, tornando-se a situação mais grave na época da chuva. Concluiu-se que há uma relação entre as doenças que atingem estas populações e a qualidade da água que consomem.

Palavras-chave: água de fontes alternativas; água para consumo humano; água tratada; doenças de veiculação hídrica; saúde pública.

\begin{abstract}
It is estimated that about $85 \%$ of diseases in developing countries are water-borne and are mainly due to the poor water quality for human consumption. In this study the physicochemical and microbiological quality of water consumed by the population of the Uíge city was assessed. Four sampling campaigns were carried out in 10 points of the public supply system, in three artesian bores and nine wells, where 21 physical and chemical and two microbiological parameters were analyzed. The results show that the water leaving the treatment is good only in the new WTP, while the water from taps and artesian bores is physicochemically suitable, but unsuitable microbiologically and the water from wells is very bad. The bacteriological contamination was detected in about $58 \%$ of samples from water taps, above $80 \%$ of samples from artesian bores and almost $100 \%$ of samples from wells, and the situation becomes worse in the rainy season. It was concluded that there is a relationship between the diseases that devastate people and the quality of the water consumed.
\end{abstract}

Keywords: alternative water sources; public health. treated water; water-borne diseases; water for human consumption. 


\section{Introdução}

Durante séculos a água foi considerada um recurso natural à disposição do homem, em quantidade infinita e autossustentável pela sua capacidade de autodepuração (Philippi, 2005). Na verdade, apenas uma parte muito pequena de toda a água do planeta pode ser aproveitada pelo homem e, ainda, para ser consumida é preciso que seja de boa qualidade. Sanchez (1996) refere que de toda água do planeta, 97,4\% é salgada, 1,8\% está sob a forma de gelo, localizando-se nas regiões polares e a água doce disponível para a população do planeta representa cerca de $0,8 \%$ do total e, mesmo assim, não se conhece bem qual é a fração que está contaminada. E, destes $0,8 \%$, somente $8 \%$ são destinados para o uso doméstico (Marquezi, 2010). Nos dias atuais a disponibilidade da água no mundo tornou-se limitada pelo comprometimento da sua qualidade. Assim, pode-se dizer que a água é um recurso renovável em quantidade, mas não em qualidade; quando se trata de água potável, não se pode considerar como recurso renovável. Shubo (2003) salienta que a escassez de água potável é um problema crónico em diversas regiões do mundo, sobretudo nos países em desenvolvimento, tornando-se uma barreira ao desenvolvimento económico e social.

A saúde humana está cada vez mais dependente da influência do crescente número de substâncias tóxicas existentes na água, no ar, nos solos e nos alimentos. Um problema extremamente grave para a saúde da população é a falta de saneamento básico e de água potável nas residências, sobretudo nos países em desenvolvimento onde estes serviços são deficientes e aproximadamente $90 \%$ dos esgotos são lançados nos cursos de água sem prévio tratamento (Marquezi, 2010). A Organização Mundial da Saúde (OMS) refere que cerca de 5 milhões de pessoas morrem anualmente de doenças transmitidas pela água, tais como tifo, cólera e infeções diarreicas e cerca de $85 \%$ das doenças conhecidas são de veiculação hídrica (WHO 2005). A água é, então um potencial veículo de transmissão de doenças quando contaminada, pelo que, nessa situação, requer tratamento apropriado para que possa ser usada para consumo humano. Assim, o desenvolvimento adequado de infraestruturas de tratamento e distribuição de água e de rede de esgotos é essencial para o desenvolvimento sustentável e melhoria da qualidade de saúde e de vida das populações.

A qualidade da água pode ser expressa através de diversos parâmetros ou indicadores de qualidade, que traduzem as suas principais características organolépticas, físicas, químicas, radioativas e biológicas. $O$ tratamento da água para consumo humano baseia-se num processo de adequação das suas características a padrões de potabilidade fixados em legislação nacional e estabelecidos com base em diretivas da OMS, que avalia o risco para a saúde humana dos contaminantes físico-químicos, microbiológicos e radiológicos presentes na água. Os critérios de qualidade da água da OMS (WHO 1996, 2006, 2011) correspondem a uma dada fase do conhecimento científico, no que se refere à relação de causa/efeito, e estão em aperfeiçoamento constante, podendo ser introduzidos novos critérios ou alterados os existentes à medida que progride o conhecimento científico. As normas de qualidade fixadas em legislação nacional poderão sofrer do mesmo modo as correções necessárias. O processo de tratamento da água pode ser menos ou mais complexo, incluindo etapas de pré- -oxidação, coagulação-floculação, decantação, filtração, afinação e desinfeção, em função da qualidade da água bruta. Quanto pior for a qualidade desta água, tanto mais complexo e caro será o seu processo de tratamento para produzir uma água potável (Boaventura, \& Leitão, 2013). O clima, especialmente no que diz respeito ao regime de precipitações, constitui um fator de origem natural que afeta as características das águas naturais superficiais (Libânio, 2010). Para além da ação natural, a ação antropogénica constitui a principal causa de contaminação ou poluição destas águas, originada principalmente pelo lançamento direto das águas residuais domésticas (contendo poluentes orgânicos, nutrientes e microrganismos patogénicos) e águas residuais industriais (que podem conter poluentes orgânicos e inorgânicos), sem tratamento ou com tratamento inadequado, e águas de drenagem das áreas agrícolas (contaminadas através do uso de fertilizantes e material em suspensão).

Angola continua sendo ainda um dos países críticos no que tange à disponibilidade de água potável e de saneamento básico para a sua população, apesar do crescimento económico que o país está registando e do grande esforço do Governo nesta área através do Plano de Acção Estratégico do Sector de Águas para o período 2004-2016 (Resolução no10/04). A saúde em Angola é ainda classificada entre as piores do mundo e o índice de doenças e mortes, sobretudo com origem na má qualidade da água, continua muito elevado. A mortalidade infantil é estimada em 76,5 por 1000 nascidos vivos (175,9 em 2011) e a esperança de vida à nascença em 56 anos, embora fosse apenas de cerca de 39 anos em 2011 (Index Mundi, 2016). 
A situação na cidade do Uíge, em particular, é historicamente drástica em termos da qualidade da água usada para o consumo das populações. Em 2013 mais de 90\% da população desta cidade não usufruía de água potável, situação que ainda não melhorou até hoje, e, nos últimos anos, esta cidade tornou-se num dos verdadeiros focos de várias endemias e epidemias, com maior destaque para as doenças de veiculação hídrica, como a cólera, a febre tifoide, as diarreias agudas e muitas outras, que originam uma boa parte dos internamentos hospitalares e até mortes. Embora a relação entre qualidade da água e saúde seja evidente, existe ainda uma grande lacuna em Angola no que se refere a estudos subsidiados para uma avaliação precisa das doenças de veiculação hídrica e dos efeitos dos múltiplos fatores ambientais sobre essas doenças. No Uíge, em particular, não há relatos de estudos deste tipo. Os resultados de um estudo preliminar realizado num passado recente (de Novembro de 2013 a Janeiro de 2014) no Hospital Provincial do Uíge, sobre a prevalência de algumas doenças de veiculação hídrica (cólera, DDA e febre tifoide) no período de 2010 a 2012, indicam uma maior prevalência nos bairros cuja população usa fontes não seguras (fontes alternativas) de água para consumo (Manuel, 2014). Apesar de não haver registos de medições de indicadores de qualidade da água nesta cidade, parece existir uma relação entre a prevalência dessas doenças e a qualidade da água consumida pela população. A tentativa de confirmar cientificamente esta suspeição motivou a realização deste trabalho, cujo objetivo geral foi de estudar a qualidade da água de diferentes proveniências consumida na cidade do Uíge, tanto do sistema de abastecimento público (água tratada) como de fontes alternativas (água não tratada). Especificamente, pretendeu-se ainda avaliar a qualidade da água em duas épocas diferentes do ano, tendo em conta a pluviosidade (estação seca/estação das chuvas), avaliar a eficiência do tratamento nas estações de tratamento de água da cidade do Uíge e propor ações que contribuam para a melhoria da oferta de água potável à população.

Angola é ainda um país em que a regulação da qualidade das águas, quer naturais (águas doces superficiais e subterrâneas), quer tratadas, não está plenamente implementada. Embora no país haja legislação que permite a classificação das águas doces superficiais destinadas à produção de água para o consumo humano (Decreto Presidencial no 261/11), não é suficientemente abrangente e detalhada, uma vez que há parâmetros de qualidade que não foram considerados e outros para os quais não são apresentados limites de concentração, causando dificuldades aos pesquisadores no uso deste diploma legal para a classificação das águas doces em estudos concretos que entendam realizar. Adicionalmente, ainda não existe legislação angolana que estabeleça adequadamente as normas de qualidade da água para o consumo humano e outros usos (rega, proteção da vida piscícola, recreio, etc.), pelo que é necessário recorrer a diretivas da OMS e a documentos legais de outros países, como por exemplo, de Portugal (Decreto-Lei no 236/98; Decreto-Lei no 306/2007), que transpõe para o direito português diretivas da União Europeia sobre qualidade da água.

\section{Materiais e Métodos}

\subsection{Caracterização da Cidade do Uíge e Respetivas Fontes de Abastecimento de Água}

Em termos urbanísticos, na cidade do Uíge, podem distinguir-se três zonas: uma zona urbana, uma zona mista e uma zona suburbana. A parte urbana (menor parte) coincide apenas com o Centro da Cidade, a mista inclui os bairros Popular no 1, Popular no 2 (Dunga), Candombe-Velho e Mbemba-Ngango e os restantes bairros são suburbanos (bairros periféricos à área urbana). De entre os bairros periféricos citam-se os bairros Papelão, Caquiuia, Quixicongo, Pedreira, Bem-Vindo, Quilala, Kilamba-Kiaxi, Cacole, Catapa, Candombe Novo, Bungo, Paco, Gai e muitos outros em formação, que crescem dia após dia de forma desordenada e caótica, com a proliferação de construções inadequadas e anárquicas e muitas destas em zonas de risco e de difícil acesso. Dados provisórios do Censo Geral da população (SPINE, 2015) apontam que até Maio de 2014 a cidade teve uma população estimada em cerca de 268.815 habitantes, que cresceu para 273.206 habitantes em Dezembro do mesmo ano, sendo que $37 \%$ desta população residia nas zonas urbana e mista.

A água para consumo da população constitui ainda um dos problemas graves na cidade do Uíge. O sistema de abastecimento público de água potável existente não satisfaz as necessidades da população, servindo apenas o Centro da Cidade, uma parte de alguns bairros urbanos (Popular, Dunga, Mbemba-Ngango) e 2 ou 3 bairros com alguns chafarizes públicos de água tratada. Esta situação tem levado a maior parte da população da cidade (acima de $90 \%$ ) a consumir água não tratada de cacimbas, furos, tanques caseiros e rios.

O fornecimento de água potável à rede pública da cidade do Uíge é feito a partir de uma captação no rio Loé para dois sistemas de tratamento: um antigo, com uma capacidade instalada de $6.000 \mathrm{m3} / \mathrm{dia}$, e um novo, com 8.000 
m3/dia de capacidade teórica, mas em que apenas $1.800 \mathrm{m3} /$ dia estão disponíveis (GPU, 2012), funcionando ambos apenas $8 \mathrm{~h} /$ dia (DPEAU, 2013). Os referidos sistemas têm assim o mesmo ponto de captação e o tratamento feito à água bruta é o convencional, compreendendo etapas de pré-oxidação, coagulação, floculação, decantação, filtração e desinfeção. No sistema antigo a água bruta é captada por bombeamento até ao poço de sedimentação, que se situa cerca de 30 metros a jusante da captação, onde por vezes se faz uma pré-oxidação, e segue para as etapas seguintes, sendo, depois de desinfetada, armazenada num reservatório subterrâneo construído em betão, de onde é bombeada para o centro de distribuição CD1, que dista mais ou menos $5 \mathrm{~km}$ da ETA antiga. No novo sistema a água é captada por meio de bombas elevatórias e levada até à ETA, que dista cerca de 1,5 km do ponto de captação, onde, à entrada, é feita a pré-oxidação, seguindo a água para as etapas seguintes do tratamento. Depois da desinfeção é armazenada num reservatório aéreo de alumínio e bombeada para o centro de distribuição $C D 2$, distando cerca de 3,5 km da ETA nova. A partir dos centros de distribuição CD1 e CD2 dos 2 sistemas, a água é fornecida aos consumidores no centro da cidade e na parte urbana dos bairros mistos por duas redes distintas, uma nova e outra antiga, cujas condutas de distribuição de água no bairro popular no 1, entrada do bairro MbembaNgango e boa parte do centro da cidade, que vai até a área do ISCED do Uíge, possuem válvulas de ligação entre a rede nova e a antiga, impossibilitando assim estudar de forma isolada a água de cada uma das redes. Até ao momento a água tratada nas duas estações de tratamento não tem dado resposta às necessidades da população. Apesar de referido atrás que diariamente são produzidos e fornecidos à população cerca de $7.800 \mathrm{~m} 3$ de água a partir das duas ETAs (GPU, 2012; DPEAU, 2013), a realidade aponta para que apenas cerca de 1/4 da população da área de estudo consome esta água, uma vez que não é distribuída diariamente e que uma boa parte da que é distribuída se perde devido a ruturas na rede e ao facto de certas torneiras públicas não fecharem devidamente.

A maior parte da população da cidade usa água de cacimbas feitas por iniciativa de pessoas privadas e comercializada pela população, sendo consumida sem nenhum tratamento. Outra fonte alternativa é a água de furos artesianos construídos pelo Governo Provincial em alguns bairros periféricos da cidade, considerada erradamente como "água potável" mas que não é submetida a nenhum tipo de tratamento. Dos 17 furos artesianos, estavam em funcionamento na altura deste estudo apenas 5 furos e 12 inoperantes há mais de um ano por avaria. Ainda outra parte da população usa água fornecida em camiões cisterna, comercializada ao preço de 1 kwanza por litro, que muitas vezes é armazenada durante semanas em tanques caseiros (subterrâneos ou aéreos). Uma boa parte desta água é proveniente de rios localizados nos arredores da cidade (rios Loé, Cangungu, Bolongonzo) e outra parte provém da ETA nova. Existem ainda famílias com meios de transporte que recorrem a aldeias vizinhas da cidade onde estão instalados chafarizes de água não tratada.

\subsection{Tipos de Águas Estudadas, Pontos e Campanhas de Amostragem}

Nesta pesquisa, foram estudadas três categorias de águas consumidas maioritariamente pela população da cidade do Uíge, que se agruparam em duas classes distintas:

1. Água tratada do Sistema de Abastecimento Público (SAP), cujo estudo se estendeu desde a água bruta a montante da captação até ao ponto de consumo;

2. Água não tratada de fontes alternativas: cacimbas e furos artesianos.

Foram usados critérios específicos e distintos para seleção dos bairros e dos pontos de amostragem para cada categoria de água pesquisada. Assim, quanto aos bairros e para o estudo da água não tratada de fontes alternativas, foram incluídos neste trabalho os principais bairros que apresentaram maior prevalência das três enfermidades de veiculação hídrica avaliadas num estudo prévio (Manuel, 2014). Para o estudo da água tratada da rede pública foram selecionados as zonas onde parte da população usufrui desta água e nas quais houve uma menor prevalência das mesmas doenças, de acordo com o estudo atrás referenciado. Com base neste critério, foram selecionados os bairros Papelão, Caquiuia, Cemiteiro, Candombe Velho, Mbemba-Ngango, Pedreira e Popular no 1 e o Centro da Cidade. Para a caracterização da água foram escolhidos 13 pontos de amostragem no sistema de abastecimento público e 12 pontos de amostragem em furos e cacimbas como ilustram as Figuras 1 e 2 . 

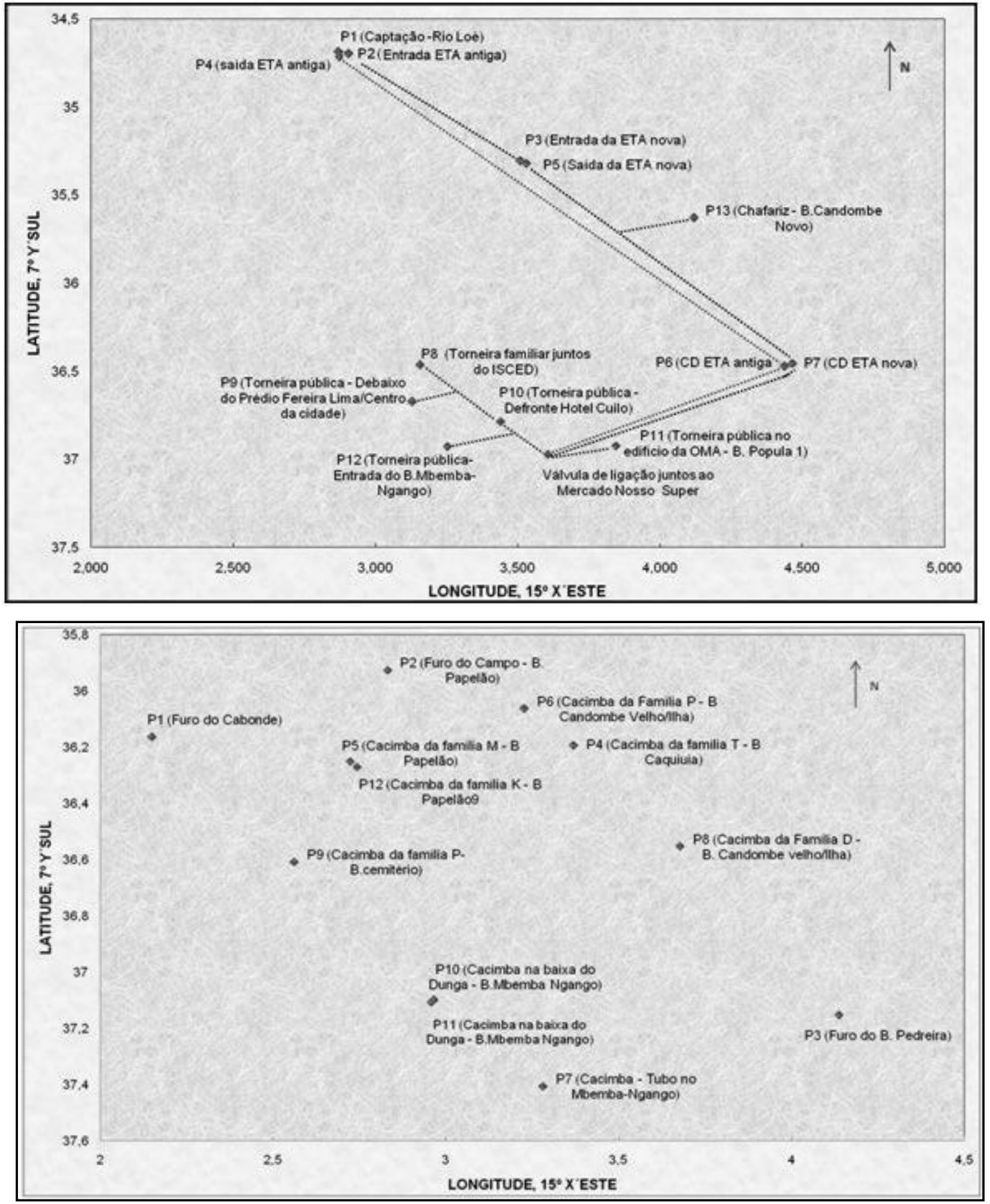

Figura 1. Mapa de localização dos potenciais pontos de amostragem: (a) água do Sistema de Abastecimento Público; (b) água do Sistema Alternativo (furos artesianos e cacimbas). 

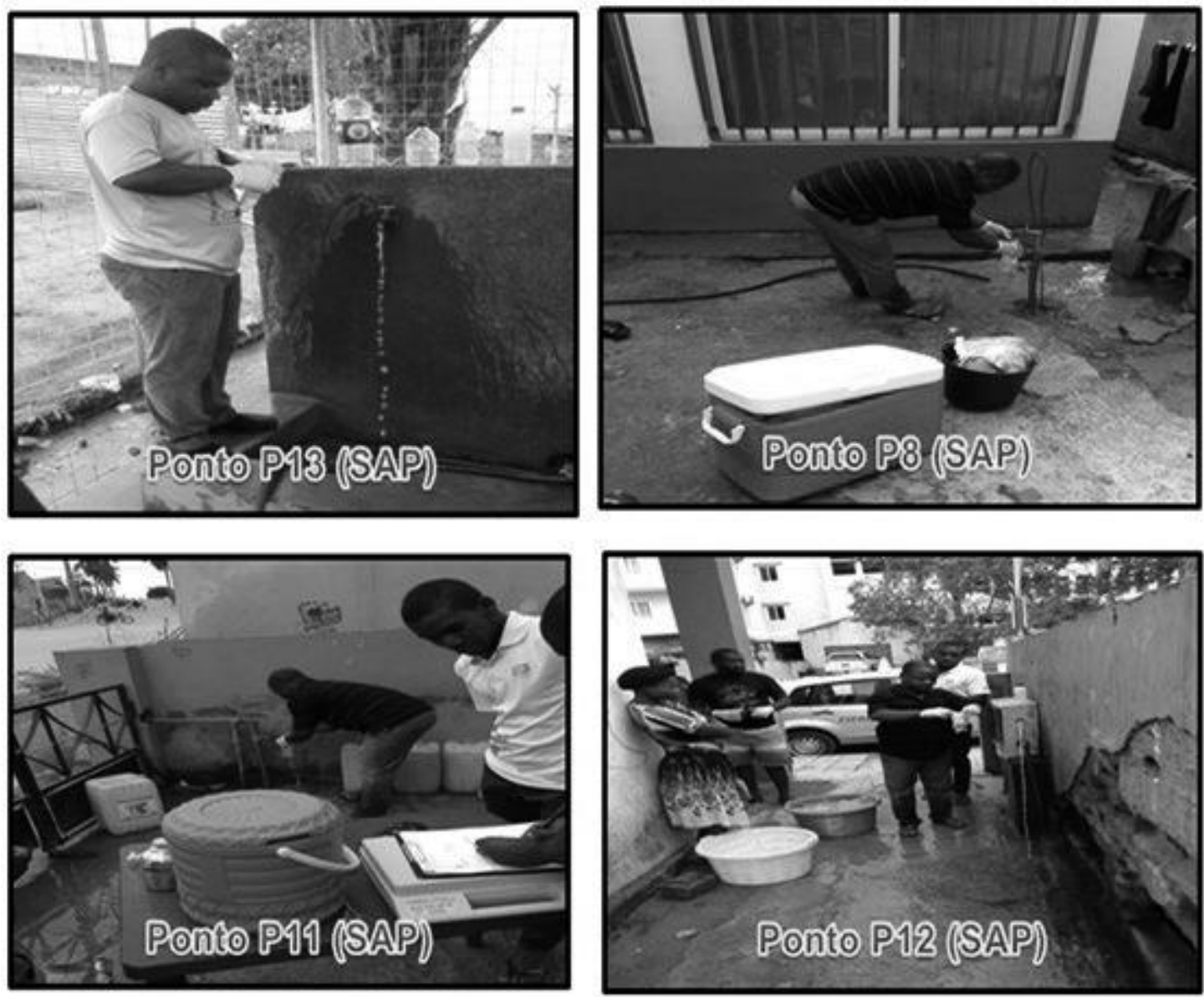

Figura 2. Alguns pontos de amostragem da água do Sistema de Abastecimento Público (SAP)

No sistema de abastecimento público, os pontos P1 (água bruta a montante da captação), P2 (água bruta à entrada da ETA antiga, junto à captação) e P3 (água bruta à entrada da ETA nova) foram selecionados com o objetivo de avaliar a qualidade da água bruta a montante da captação e à entrada das ETAs; os pontos P4 e P5 tiveram como missão avaliar a qualidade da água tratada à saída das ETAs e os pontos P6 e P7 destinavam-se a medir a qualidade da água tratada armazenada nos centros de distribuição, dando uma ideia geral sobre a eficiência do tratamento e a qualidade da água tratada armazenada para ser distribuída à população. Não obstante o interesse, os pontos P2, P6 e P7 foram excluídos do estudo, por ausência de torneiras que possibilitassem a recolha de água nestes locais. Os restantes seis pontos (P8, P9, P10, P11, P12 e P13) foram selecionados de forma a avaliar a qualidade da água tratada ao longo da rede de distribuição. Nas fontes alternativas, os pontos P1, P2 e P3 são águas de furos artesianos e de P4 a P12 são águas das cacimbas.

Foram realizadas quatro campanhas de amostragem para cada sistema de água em estudo, nos pontos referidos acima para cada sistema, no período compreendido entre Julho e Dezembro de 2014, sendo duas na época seca e duas na época das chuvas, como se mostra na Tabela 1.

Tabela 1. Calendário da realização das campanhas de amostragem.

\begin{tabular}{|c|c|c|c|}
\hline $\begin{array}{c}\text { Campanhas de } \\
\text { amostragem }\end{array}$ & Tipos de água a analisar & Colheita (*) & Análise no laboratório \\
\cline { 3 - 4 } & $\begin{array}{c}\text { Água do Sistema de } \\
\text { Abastecimento Público }\end{array}$ & $13 / 07 / 2014$ & 14 a 18/07/2014 \\
\hline $\begin{array}{c}\text { Primeira campanha da seca } \\
\text { época }\end{array}$ & $\begin{array}{c}\text { Água de fontes alternativas } \\
\text { (cacimbas e furos artesianos) }\end{array}$ & $20 / 07 / 2014$ & 21 a 24/07/2014 \\
\cline { 2 - 4 } & Água do Sistema de Abastecimento & $10 / 08 / 2014$ & 11 a 14/08/2014 \\
\hline
\end{tabular}

Revista Internacional em Língua Portuguesa, 2018, №33, Ciências da Saúde e Tecnologia, pp. 75-93 


\begin{tabular}{|c|c|c|c|}
\hline época Seca & Público & $17 / 08 / 2014$ & 18 a 21/08/2014 \\
\cline { 2 - 4 } & $\begin{array}{c}\text { Água de fontes alternativas } \\
\text { (cacimbas e furos artesianos) }\end{array}$ & $24 / 11 / 2014$ & 25 a $29 / 11 / 2014$ \\
\hline \multirow{2}{*}{$\begin{array}{c}\text { Primeira campanha da } \\
\text { época das chuvas }\end{array}$} & $\begin{array}{c}\text { Água do Sistema de Abastecimento } \\
\text { Público }\end{array}$ & $03 / 11 / 2014$ & 04 a $08 / 11 / 2014$ \\
\cline { 2 - 4 } (cacimbas e furos artesianos) & Água do Sistema de Abastecimento \\
Público & $08 / 12 / 2014$ & 09 a $13 / 12 / 2014$ \\
\hline $\begin{array}{c}\text { Segunda campanha da } \\
\text { época das chuvas }\end{array}$ & $\begin{array}{c}\text { Água de fontes alternativas } \\
\text { (cacimbas e furos artesianos) }\end{array}$ & $01 / 12 / 2014$ & 02 a $06 / 12 / 2014$ \\
\hline
\end{tabular}

$\left({ }^{*}\right)$ Incluindo análises in situ.

As amostras foram colhidas seguindo o padrão estabelecido no Manual "Standard Methods for the Examination of Water and Wastewater" (Eaton et al., 2005). Assim, as amostras de água tratada e as de água não tratada para análises microbiológicas foram recolhidas para 2 recipientes distintos: (a) as de água tratada foram guardadas em bolsas de plástico descartáveis apropriadas (Thio-Bag Whirl- Pak), com capacidade de $100 \mathrm{ml}$, contendo uma pastilha de tiossulfato de sódio (para a neutralização de um possível cloro residual), e (b) as de água não tratada foram colectadas em garrafas de plástico de $500 \mathrm{ml}$ previamente esterilizadas, fornecidas pelo laboratório da AmbiÁfrica. Para os ensaios físico-químicos, com excepção da determinação da matéria orgânica, as amostras foram colhidas em garrafas de plástico de água mineral Sesse, com a capacidade volumétrica de 1,5 litro, que não sofreram qualquer tipo de preparação específica. Logo após a colheita, todas as amostras foram acondicionadas em caixas isotérmicas, mantidas sob refrigeração, e transportadas para Luanda num prazo máximo de 14 horas para o Laboratório de Engenharia de Separação, Reacção Química e Ambiente (LESRA) e laboratório da AmbiÁfrica para determinação de diversos parâmetros obedecendo a métodos padronizados (Eaton et al., 2005). As análises microbiológicas foram iniciadas antes de estarem esgotadas as 24 horas após a colheita das amostras.

\subsection{Parâmetros Analisados e Metodologias Analíticas}

A seleção dos parâmetros a analisar e a avaliação do cumprimento dos respetivos valores paramétricos ou limite baseou-se principalmente na legislação portuguesa (Decreto-Lei no 306/2007 e Decreto-Lei no 236/98) e nas Diretivas da OMS (WHO, 2011, 2006). As metodologias analíticas adotadas para a determinação dos principais parâmetros constam da Tabela 2. Para os restantes parâmetros foram utilizados métodos referidos no Manual Standard Methods for the Examination of Water and Wastewater (Eaton et al., 2005).

Os parâmetros físico-químicos analisados neste estudo foram: cheiro, sabor, turvação, pH, oxigénio dissolvido (OD), condutividade, sólidos dissolvidos totais (SDT), cloro residual livre (CRL), cor, oxidabilidade, alcalinidade total, dureza total, cálcio, magnésio, ferro, sódio, potássio, azoto amoniacal, nitratos, ortofosfatos e alumínio. Destes, foram medidos no local de amostragem os seguintes: $\mathrm{pH}, \mathrm{OD}$, turvação, condutividade, SDT, cloro residual livre, cheiro e sabor, utilizando aparelhos de medida portáteis. A Tabela 2 mostra os parâmetros determinados no Laboratório de Engenharia da Separação, Reacção Química e Ambiente da Universidade Agostinho Neto (LESRA), em Luanda, métodos, técnicas e equipamentos usados.

Tabela 2. Parâmetros, métodos, técnicas e equipamentos utilizados

\begin{tabular}{|c|c|c|}
\hline Parâmetro (Unidade) & Método* & Técnica/Equipamento \\
\hline Oxidabilidade (mg/L) & $\begin{array}{l}\text { Volumétrico de oxidação-redução } \\
\text { NP-731* }\end{array}$ & $\begin{array}{c}\text { Titulação/Placa de aquecimento e placa } \\
\text { magnética }\end{array}$ \\
\hline Alcalinidade (mg CaCO3/L) & $\begin{array}{l}\text { Volumétrico e Potenciométrico } \\
\text { SMEWW } 2320 \mathrm{~B}^{* *}\end{array}$ & $\begin{array}{l}\text { Titulação e eletrometria/Placa de agitação e } \\
\text { medidor de } \mathrm{pH}\end{array}$ \\
\hline Dureza total (mg CaCO3/L) & $\begin{array}{l}\text { Volumétrico de complexação } \\
\text { SMEWW } 2340 \text { C }\end{array}$ & Titulação/ Placa de agitação \\
\hline $\begin{array}{l}\text { Cálcio } \\
\text { (mg/L) }\end{array}$ & $\begin{array}{l}\text { Volumétrico de complexação } \\
\text { SMEWW 3500-Ca B. }\end{array}$ & Titulação/ Placa de agitação \\
\hline Magnésio & Volumétrico de complexação & Titulação/ Placa de agitação e orbital \\
\hline
\end{tabular}




\begin{tabular}{|c|c|c|}
\hline$(\mathrm{mg} / \mathrm{L})$ & SMEWW 3500-Mg B. & Shaker \\
\hline $\begin{array}{l}\text { Ferro } \\
(\mathrm{mg} / \mathrm{L})\end{array}$ & $\begin{array}{l}\text { Absorção molecular } \\
\text { Método da Fenantrolina } \\
\text { SMEWW 3500-Fe B. }\end{array}$ & $\begin{array}{l}\text { Espectrofotometria/Espectrofotómetro } \\
\text { UV/VIS de marca CECIL modelo CE292 } \\
\text { série } 2\end{array}$ \\
\hline $\begin{array}{l}\text { Sódio } \\
\text { (mg/L) }\end{array}$ & $\begin{array}{l}\text { Emissão atómica por chama } \\
\text { SMEWW 3500-Na B. }\end{array}$ & $\begin{array}{l}\text { Fotometria de chama/Fotómetro de chama de } \\
\text { marca JENWAY modelo PFP7 }\end{array}$ \\
\hline $\begin{array}{l}\text { Potássio } \\
\text { (mg/L) }\end{array}$ & $\begin{array}{l}\text { Emissão atómica por chama } \\
\text { SMEWW 3500-K B. }\end{array}$ & $\begin{array}{l}\text { Fotometria de chama/Fotómetro de chama de } \\
\text { marca JENWAY modelo PFP7 }\end{array}$ \\
\hline $\begin{array}{l}\text { Alumínio } \\
(\mathrm{mg} / \mathrm{L})\end{array}$ & $\begin{array}{c}\text { Absorção molecular } \\
\text { Método da Cianina de Eriocromo } \\
\text { SMEWW 3500-Al B. }\end{array}$ & $\begin{array}{l}\text { Espectrofotometria/Espectrofotómetro } \\
\text { UV/VIS de marca CECIL modelo CE292 } \\
\text { série } 2(\lambda=535 \mathrm{~nm})\end{array}$ \\
\hline $\begin{array}{c}\text { Cor } \\
\text { (mg Pt-Co/L) }\end{array}$ & $\begin{array}{l}\text { Absorção molecular } \\
\text { SMEWW } 2120 \text { C. }\end{array}$ & $\begin{array}{l}\text { Espectrofotometria/Espectrofotómetro } \\
\text { UV/VIS de marca CECIL modelo CE292 } \\
\qquad(\lambda=470 \mathrm{~nm}) \\
\end{array}$ \\
\hline $\begin{array}{l}\text { Ortofosfatos } \\
\qquad(\mathrm{mg} / \mathrm{L})\end{array}$ & $\begin{array}{l}\text { Absorção molecular } \\
\text { SMEWW } 4500 \text { P E. }\end{array}$ & $\begin{array}{l}\text { Espectrofotometria/Espectrofotómetro } \\
\text { UV/VIS de marca CECIL modelo CE292 } \\
(\lambda=880 \mathrm{~nm})\end{array}$ \\
\hline $\begin{array}{l}\text { Azoto amoniacal } \\
(\mathrm{mg} / \mathrm{L})\end{array}$ & $\begin{array}{c}\text { Potenciométrico } \\
\text { SMEWW 4500-NH3 D. }\end{array}$ & Eletrometria/Elétrodo seletivo de amónia \\
\hline $\begin{array}{l}\text { Nitratos } \\
(\mathrm{mg} / \mathrm{L})\end{array}$ & $\begin{array}{c}\text { Potenciométrico } \\
\text { SMEWW 4500-NO3 D. }\end{array}$ & Eletrometria/Elétrodo de ião seletivo \\
\hline Turvação & $\begin{array}{l}\text { Nefelométrico } \\
\text { SMEWW } 2130 \text { B. }\end{array}$ & $\begin{array}{c}\text { Turbidímetro de marca HACH LANGE } \\
\text { modelo } 2100 \mathrm{P}\end{array}$ \\
\hline
\end{tabular}

* NP (Norma Portuguesa);

**SMEWW (Standard Methods for the Examination of Water and Wastewater)

Em termos de parâmetros microbiológicos, foi realizada uma análise qualitativa (presença/ausência) de coliformes totais e de Escherichia Coli (E.Coli). Os testes de presença/ausência de coliformes totais e E.coli foram realizados usando dois métodos distintos e em locais diferentes. No método implementado in situ foram usados kits de campo (Bacteriological Field Testing Kit, Cat. No. OR-BAC-02 da ORLAB Instruments PVT-LTD), fornecidos pela Direcção Nacional de Águas, em que $20 \mathrm{ml}$ de cada amostra foi colocado num frasco de teste contendo o substrato na forma de pó. Após a homogeneização das amostras nos frascos, estes foram colocados numa incubadora de campo a uma temperatura de 25 a 35 ㄷ C durante 24 horas. Após o período de incubação, a coloração preta indicava a presença de coliformes totais e E. Coli e a coloração amarela (coloração inicial após homogeneização) indicava a ausência dos dois tipos de coliformes. O método implementado no laboratório da AmbiÁfrica foi o método COLILERT (IDEXX Laboratories, Inc. EUA). Neste método adicionou-se o reagente (COLILERT) à amostra transferida para frasco de 100 $\mathrm{ml}$ e levou-se à incubadora durante 24 horas a $35 \circ \mathrm{C}$. O COLILERT utiliza tecnologia de substrato definido para deteç̧ão de coliformes totais e E.Coli em água. Após o período de incubação, a coloração amarela indicava a presença de coliformes totais e a fluorescência, sob luz UV (365 nm) no escuro, indicava a presença de E. coli.

\section{Resultados e Discussão}

Neste trabalho, cada parâmetro, determinado em cada ponto e campanha de amostragem, foi comparado com o correspondente valor paramétrico para avaliação da conformidade no que se refere ao uso da água para consumo humano, como se ilustra com o parâmetro oxidabilidade nas Figuras 3(a) e 4(a) para a água do sistema de abastecimento público e alternativo (furos artesianos e cacimbas), respetivamente. 

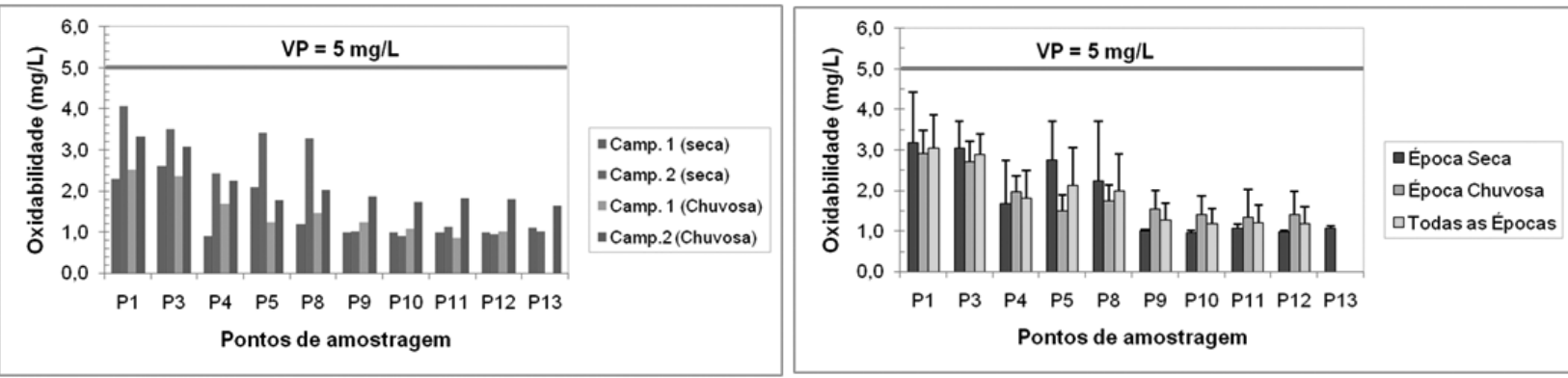

Figura 3. Variação da oxidabilidade na água do Sistema de Abastecimento Público: (a) valores em cada campanha; (b) valores médios em cada época. VP = Valor Paramétrico segundo Decreto-Lei no 306/2007 (legislação portuguesa).
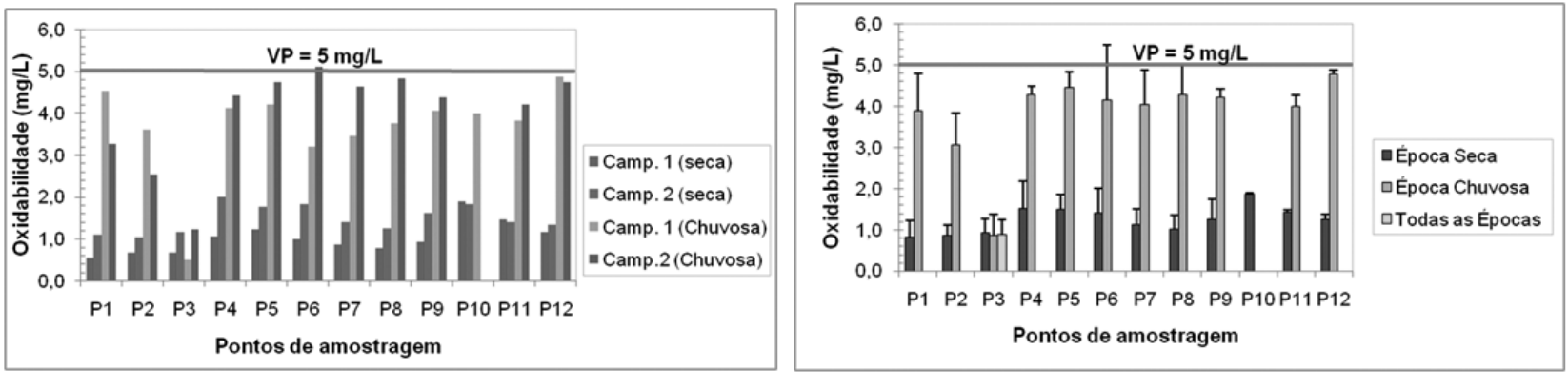

Figura 4. Variação da oxidabilidade na água do Sistema Alternativo (furos e cacimbas):

(a) valores em cada campanha, (b) valores médios em cada época.

VP = Valor Paramétrico segundo Decreto-Lei no 306/2007 (legislação portuguesa).

A água do sistema de abastecimento público apresentou valores da oxidabilidade na gama de 2,3 a $4,1 \mathrm{mg} \mathrm{O}_{2} / \mathrm{L}$ na água bruta, de 0,9 a 3,4 $\mathrm{mg} \mathrm{O}_{2} / \mathrm{L}$ à saída da linha do tratamento e de 0,9 a $3,3 \mathrm{mg} \mathrm{O}_{2} / \mathrm{L}$ na rede de distribuição, valores que estão abaixo do limite fixado $(5 \mathrm{mg} \mathrm{O} / \mathrm{L}$ ) nos diplomas para avaliação da qualidade da água usados neste estudo. As águas das fontes alternativas apresentam maior variabilidade de ponto para ponto, tendo sido obtidos valores mais baixos da oxidabilidade na água de furos artesianos (na gama de 0,5 a 4,5 mg $\mathrm{O}_{2} / \mathrm{L}$ ) e valores mais elevados nas cacimbas, variando de 0,8 a 5,1 $\mathrm{mg} \mathrm{O}_{2} / \mathrm{L}$, destacando-se o ponto P6 que, na 2 a colheita da época chuvosa, apresentou uma oxidabilidade ligeiramente superior ao valor paramétrico.

Adicionalmente, por se terem realizado duas campanhas de amostragem em cada época climática, foram calculados os valores médios de cada parâmetro obtidos em cada época e ponto de amostragem e feita uma análise estatística, usando o teste T, para verificar a existência de diferenças significativas (nível de confiança de 0,95) entre os valores médios do parâmetro para as duas épocas climáticas. O valor médio para o conjunto das duas épocas (4 campanhas) foi calculado apenas nos pontos em que não se registou diferença significativa entre as médias calculadas para as duas épocas separadamente. A título de exemplo, na Figura 3(b) mostra-se que não houve influência significativa das chuvas sobre a oxidabilidade da água em todos os pontos de amostragem do sistema de abastecimento público. No ponto 13 não foi calculado o valor médio para a época chuvosa, por não se ter tido acesso a este ponto na 1 a campanha da época chuvosa. No caso do sistema alternativo, a análise estatística revelou que há uma diferença significativa entre os valores médios das duas épocas em todos os pontos, com exceção do ponto P3, sendo notório o aumento do teor de matéria orgânica na época chuvosa, como ilustrado na Figura 4(b).

O resultado da análise feita parâmetro a parâmetro para os dois sistemas de abastecimento de água apresenta-se de forma condensada nas Tabelas 3 a 6 . Nas Tabelas 3 e 4 mostram-se os valores médios dos parâmetros de qualidade que nem sempre respeitam os valores paramétricos da água para consumo humano no sistema de abastecimento público e no sistema alternativo, respetivamente, nas duas épocas climáticas (estação seca e estação da chuva). 
Tabela 3. Parâmetros de qualidade da água que não respeitam os valores paramétricos para consumo humano no Sistema Público de Distribuição de água (a sombreado).

\begin{tabular}{|c|c|c|c|c|c|c|c|c|}
\hline $\begin{array}{c}\text { Ponto de } \\
\text { amostragem }\end{array}$ & $\begin{array}{c}\text { Al } \\
(\mu \mathrm{g} / \mathrm{L})\end{array}$ & $\begin{array}{c}\mathrm{N}-\mathrm{NH}_{4}^{+} \\
\left(\mathrm{mg} \mathrm{NH}_{4} / \mathrm{L}\right)\end{array}$ & $\begin{array}{c}\text { Cloro } \\
\text { res. livre } \\
\text { (mg/L) }\end{array}$ & $\begin{array}{c}\text { Cor } \\
\text { (Pt-Co/L) }\end{array}$ & $\begin{array}{c}\mathrm{Fe} \\
(\mu \mathrm{g} / \mathrm{L})\end{array}$ & $\begin{array}{l}\text { Turv. } \\
\text { (UNT) }\end{array}$ & $\begin{array}{l}\text { Colif. } \\
\text { totais }\end{array}$ & $\begin{array}{c}\text { E. coli } \\
-\end{array}$ \\
\hline \multicolumn{9}{|c|}{ ÉPOCA SECA } \\
\hline P1* & 13 & 0,04 & - & 13,4 & 218 & 15,4 & Presença & Presença \\
\hline P3* & 53 & 0,03 & - & 14,5 & 765 & 15,1 & Presença & Presença \\
\hline P4 & 199 & 0,03 & 1,1 & 5,7 & 100 & 1,9 & Presença & Presença \\
\hline P5 & 162 & 0,03 & 2,3 & 2,7 & 30 & 0,8 & Ausência & Ausência \\
\hline P8 & 130 & 2,68 & 0,2 & 10,3 & 50 & 9,5 & Presença & Presença \\
\hline P9 & 244 & 0,04 & 0,9 & 2,7 & 35 & 1,5 & Ausência & Ausência \\
\hline P10 & 218 & 0,04 & 0,9 & 1,6 & 255 & 1,1 & Ausência & Ausência \\
\hline P11 & 247 & 0,03 & 1,1 & 2,7 & 15 & 2,7 & Ausência & Ausência \\
\hline P12 & 284 & 0,03 & 1,0 & 1,6 & 485 & 1,1 & Ausência & Ausência \\
\hline P13 & 202 & 0,03 & 2,0 & 1,6 & 55 & 0,8 & Ausência & Ausência \\
\hline \multicolumn{9}{|c|}{ ÉPOCA DA CHUVA } \\
\hline P1* & 276 & 0,47 & - & 31,4 & 206 & 24,5 & Presença & Presença \\
\hline P3* & 146 & 0,32 & - & 17,0 & 344 & 19,8 & Presença & Presença \\
\hline P4 & 298 & 0,43 & 1,5 & 20,1 & 33 & 1,4 & Presença & Presença \\
\hline P5 & 212 & 0,31 & 3,6 & 1,6 & 64 & 2,4 & Ausência & Ausência \\
\hline P8 & 219 & 0,53 & 0,1 & 2,7 & 84 & 10,2 & Presença & Presença \\
\hline P9 & 227 & 0,49 & 0,3 & 2,1 & 79 & 6,1 & Presença & Presença \\
\hline $\mathrm{P} 10$ & 220 & 0,52 & 1,2 & 1,6 & 69 & 5,1 & Presença & Presença \\
\hline P11 & 261 & 0,40 & 1,3 & 2,7 & 26 & 3,6 & Presença & Presença \\
\hline $\mathrm{P} 12$ & 245 & 0,38 & 1,4 & 1,6 & 24 & 4,4 & Presença & Presença \\
\hline $\mathrm{P} 13$ & - & - & - & - & - & - & Ausência & Ausência \\
\hline VP** & 200 & 0,50 & $0,2-0,6$ & 20 & 200 & 4 & Ausência & Ausência \\
\hline
\end{tabular}

*Água bruta superficial destinada a tratamento.

**Valor Paramétrico segundo o Decreto-Lei n 306/2007 (legislação portuguesa).

Tabela 4. Parâmetros de qualidade da água que não respeitam os valores paramétricos para consumo humano no Sistema Alternativo de furos artesianos e cacimbas (a sombreado).

\begin{tabular}{|c|c|c|c|c|c|c|c|c|}
\hline $\begin{array}{c}\text { Ponto de } \\
\text { amostragem }\end{array}$ & $\begin{array}{c}\mathrm{pH} \\
-\end{array}$ & $\begin{array}{c}\text { Nitratos } \\
\left(\mathrm{mg} \mathrm{NO}_{3} / \mathrm{L}\right)\end{array}$ & $\begin{array}{c}\mathrm{N}-\mathrm{NH} 4+ \\
\left(\mathrm{mg} \mathrm{NH}_{4} / \mathrm{L}\right)\end{array}$ & $\begin{array}{c}\text { Cor } \\
\text { (Pt-Co/L) }\end{array}$ & $\begin{array}{c}\mathrm{Fe} \\
(\mu \mathrm{g} / \mathrm{L})\end{array}$ & $\begin{array}{l}\text { Turv. } \\
\text { (UNT) }\end{array}$ & $\begin{array}{l}\text { Colif. } \\
\text { totais }\end{array}$ & $\begin{array}{c}\text { E. coli } \\
-\end{array}$ \\
\hline \multicolumn{9}{|c|}{ ÉPOCA SECA } \\
\hline P1 & 7,6 & 0,03 & 2,1 & 2,1 & 0 & 0,3 & Presença & Presença \\
\hline $\mathrm{P} 2$ & 7,6 & 0,02 & 2,7 & 2,7 & 24 & 3,9 & Presença & Presença \\
\hline P3 & 7,1 & 0,01 & 2,7 & 2,7 & 7 & 0,6 & Presença & Presença \\
\hline P4 & 7,1 & 0,02 & 4,7 & 4,7 & 44 & 19,2 & Presença & Presença \\
\hline P5 & 7,1 & 0,02 & 22,1 & 22,1 & 238 & 43,1 & Presença & Presença \\
\hline P6 & 7,3 & 0,02 & 7,8 & 7,8 & 117 & 18,5 & Presença & Presença \\
\hline P7 & 7,0 & 0,02 & 1,6 & 1,6 & 522 & 1,1 & Presença & Presença \\
\hline P8 & 6,9 & 0,02 & 1,6 & 1,6 & 0 & 5,6 & Presença & Presença \\
\hline P9 & 6,8 & 0,02 & 6,8 & 6,8 & 148 & 8,8 & Presença & Presença \\
\hline P10 & 6,8 & 0,18 & 5,7 & 5,7 & 73 & 2,8 & Presença & Presença \\
\hline P11 & 4,8 & 0,09 & 3,2 & 3,2 & 234 & 9,2 & Presença & Presença \\
\hline P12 & 6,3 & 0,04 & 3,2 & 3,2 & 154 & 8,4 & Presença & Presença \\
\hline \multicolumn{9}{|c|}{ ÉPOCA DA CHUVA } \\
\hline P1 & 7,6 & 18,5 & 1,30 & 1,6 & 15 & 0,6 & Presença & Presença \\
\hline $\mathrm{P} 2$ & 7,5 & 28,1 & 1,27 & 1,6 & 21 & 0,4 & Presença & Presença \\
\hline P3 & 7,2 & 26,5 & 0,49 & 1,6 & 23 & 1,0 & Presença & Presença \\
\hline P4 & 7,0 & 73,0 & 1,89 & 3,2 & 62 & 8,2 & Presença & Presença \\
\hline P5 & 7,0 & 38,3 & 1,68 & 14,5 & 96 & 9,2 & Presença & Presença \\
\hline P6 & 7,5 & 29,8 & 2,13 & 16,7 & 45 & 32,0 & Presença & Presença \\
\hline
\end{tabular}




\begin{tabular}{|c|c|c|c|c|c|c|c|c|}
\hline P7 & 6,9 & 30,2 & 1,37 & 3,7 & 30 & 3,0 & Presença & Presença \\
\hline P8 & 6,9 & 45,5 & 1,54 & 4,2 & 32 & 1,6 & Presença & Presença \\
\hline P9 & 6,5 & 35,5 & 1,57 & 38,0 & 206 & 35,4 & Presença & Presença \\
\hline P10 & - & - & - & - & - & - & Presença & Presença \\
\hline P11 & 6,3 & 21,7 & 2,64 & 12,4 & 69 & 6,9 & Presença & Presença \\
\hline P12 & 5,3 & 15,7 & 2,68 & 52,2 & 22 & 32,4 & Presença & Presença \\
\hline VP* & $6,5-9$ & 50 & 0,5 & 20 & 200 & 4 & Ausência & Ausência \\
\hline
\end{tabular}

*Valor Paramétrico segundo o Decreto-Lei no 306/2007 (legislação portuguesa)

Para estes dois sistemas, nas Tabelas 5 e 6 apresentam-se os parâmetros com valores médios superiores na época seca ou com valores médios superiores na época da chuva, sendo apresentados a negrito os parâmetros em que se registaram as maiores diferenças.

Tabela 5. Comparação dos valores dos parâmetros de qualidade da água nas épocas seca e da chuva no Sistema Público de Distribuição de água.

\begin{tabular}{|c|c|c|}
\hline \multirow{2}{*}{$\begin{array}{c}\text { Ponto de } \\
\text { Amostragem }\end{array}$} & \multicolumn{2}{|c|}{ Parâmetros } \\
\hline & Com valores superiores na época seca & Com valores superiores na época da chuva \\
\hline P1 & $\mathrm{pH}, \mathrm{OD}$, Oxid, Alc, Dur, Ca, Mg, $\mathrm{Fe}, \mathrm{Na}$ & Turv, Cor, Cond, SDT, $\mathrm{K}, \mathrm{NH}_{4}, \mathrm{NO}_{3}, \mathrm{P}, \mathrm{Al}$ \\
\hline P3 & OD, Oxid, Alc, Mg, Fe, $\mathrm{Na}$ & $\mathrm{pH}$, Turv , Cor, Cond, SDT, Dur, Ca, K, NH4, NO3, P, Al \\
\hline P4 & OD, Turv, Cor, $\mathrm{Mg}, \mathrm{Fe}, \mathrm{Na}$ & $\begin{array}{c}\mathrm{pH}, \text { Cond, SDT, Oxid, Alc, Dur, } \mathrm{Ca}, \mathrm{K}, \mathrm{NH}_{4} \\
\mathrm{NO}_{3}, \mathrm{P}, \mathrm{Al}\end{array}$ \\
\hline P5 & $\mathrm{pH}, \mathrm{Cor}, \mathrm{Oxid}, \mathrm{Mg}, \mathrm{Na}$ & $\begin{array}{l}\text { OD, Turv, Cond, SDT, Alc, Dur, } \mathrm{Ca}, \mathrm{Fe}, \mathrm{K}, \\
\mathrm{NH}_{4}, \mathrm{NO}_{3}, \mathrm{P}, \mathrm{Al}\end{array}$ \\
\hline P8 & $\mathrm{pH}, \mathrm{OD}, \mathrm{Cor}, \mathrm{Oxid}, \mathrm{Alc}, \mathrm{Mg}, \mathrm{Na}, \mathrm{K}, \mathrm{NH}_{4}$ & Turv, Cond, SDT, Dur, $\mathrm{Ca}, \mathrm{Fe}, \mathrm{NO}_{3}, \mathrm{P}, \mathrm{Al}$ \\
\hline P9 & pH, OD, Cor, Alc, $\mathrm{Na}, \mathrm{Al}$ & $\begin{array}{l}\text { Turv, Cond, SDT, Oxid, Dur, } \mathrm{Ca}, \mathrm{Mg}, \mathrm{Fe}, \mathrm{K} \\
\qquad \mathrm{NH}_{4}, \mathrm{NO}_{3}, \mathrm{P}\end{array}$ \\
\hline P10 & $\mathrm{pH}, \mathrm{OD}, \mathrm{Alc}, \mathrm{Fe}, \mathrm{Na}$ & $\begin{array}{c}\text { Turv, Cond, SDT, Oxid, Dur, } \mathrm{Ca}, \mathrm{Mg}, \mathrm{K}, \mathrm{NH}_{4} \\
\qquad \mathrm{NO}_{3}, \mathrm{P}, \mathrm{A}\end{array}$ \\
\hline P11 & $\mathrm{pH}, \mathrm{Na}$ & $\begin{array}{c}\text { OD, Turv, Cond, SDT, Oxid, Alc, Dur, } \mathrm{Ca}, \mathrm{Mg} \text {, } \\
\mathrm{Fe}, \mathrm{K}, \mathrm{NH}_{4}, \mathrm{NO}_{3}, \mathrm{P}, \mathrm{Al}\end{array}$ \\
\hline P12 & pH, OD, Alc, Fe, Na, Al & $\begin{array}{l}\text { Turv, Cond, SDT, Oxid, Dur, } \mathrm{Ca}, \mathrm{Mg}, \mathrm{K}, \mathrm{NH}_{4} \\
\mathrm{NO}_{3}, \mathrm{P}\end{array}$ \\
\hline P13 & - & - \\
\hline
\end{tabular}

Nota: os parâmetros para os quais se registaram maiores diferenças estão escritos a negrito.

Tabela 6. Comparação dos valores dos parâmetros de qualidade da água nas épocas seca e da chuva no Sistema Alternativo (furos artesianos e cacimbas).

\begin{tabular}{|c|c|c|}
\hline \multirow{2}{*}{$\begin{array}{c}\text { Ponto de } \\
\text { Amostragem }\end{array}$} & \multicolumn{2}{|c|}{ Parâmetros } \\
\hline & Com valores superiores na época seca & Com valores superiores na época da chuva \\
\hline P1 & $\mathrm{pH}, \mathrm{OD}, \mathrm{Cor}, \mathrm{Na}, \mathrm{P}$ & $\begin{array}{c}\text { Turv, Cond, SDT, Oxid, Alc, Dur, } \mathrm{Ca}, \mathrm{Mg}, \mathrm{Fe}, \\
\qquad, \mathrm{NH}_{4}, \mathrm{NO}_{3}\end{array}$ \\
\hline $\mathrm{P} 2$ & $\mathrm{pH}, \mathrm{OD}$, Turv, Cor, $\mathrm{Mg}, \mathrm{Na}$ & Cond, SDT, Oxid, Alc, Dur, $\mathrm{Ca}, \mathrm{Fe}, \mathrm{K}, \mathrm{NH}_{4}, \mathrm{NO}_{3}, \mathrm{P}$ \\
\hline P3 & OD, Cor, Oxid, $\mathrm{Ca}, \mathrm{Mg}, \mathrm{Na}, \mathrm{P}$ & $\mathrm{pH}$, Turv, Cond, SDT, Alc, Dur, Fe, $\mathrm{K}, \mathbf{N H}_{4}, \mathbf{N O}_{3}$ \\
\hline P4 & $\mathrm{pH}, \mathrm{OD}$, Turv, Cor, $\mathrm{Mg}, \mathrm{Na}, \mathrm{P}$ & Cond, SDT, Oxid, Alc, Dur, $\mathrm{Ca}, \mathrm{Fe}, \mathrm{K}, \mathrm{NH}_{4}, \mathbf{N O}_{3}$ \\
\hline P5 & $\mathrm{pH}$, OD, Turv, Cor, Alc, Ca, Mg, Fe, P & Cond, SDT, Oxid, Dur, $\mathrm{Na}, \mathbf{K}, \mathrm{NH}_{4}, \mathrm{NO}_{3}$ \\
\hline P6 & OD, Alc, Fe, Na, K & $\begin{array}{l}\text { pH, Turv, Cor, Cond, SDT, Oxid, Dur, } \mathrm{Ca}, \mathrm{Mg} \text {, } \\
\mathrm{NH}_{4}, \mathrm{NO}_{3}, \mathrm{P}\end{array}$ \\
\hline P6 & $\mathrm{pH}, \mathrm{OD}, \mathrm{Dur}, \mathrm{Mg}, \mathrm{Fe}, \mathrm{Na}, \mathrm{K}$ & Turv, Cor, Cond, SDT, Oxid, Alc, $\mathrm{Ca}, \mathrm{NH}_{4}, \mathrm{NO}_{3}, \mathrm{P}$ \\
\hline P8 & $\mathrm{pH}, \mathrm{OD}, \mathrm{Turv}, \mathrm{Mg}, \mathrm{Na}, \mathrm{P}$ & Cor, Cond, SDT, Oxid, Alc, Dur, $\mathrm{Ca}, \mathrm{Fe}, \mathrm{K}, \mathrm{NH}_{4}, \mathrm{NO}_{3}$ \\
\hline P9 & $\mathrm{pH}, \mathrm{OD}$, Cond, SDT, Alc, $\mathrm{Ca}, \mathrm{Mg}, \mathrm{Na}$ & Turv, Cor, Oxid, Dur, $\mathrm{Fe}, \mathrm{K}, \mathrm{NH}_{4}, \mathrm{NO}_{3}, \mathrm{P}$ \\
\hline \multicolumn{3}{|r|}{ 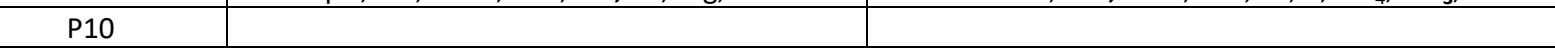 } \\
\hline P11 & OD, Turv, Alc, Ca, Mg, Fe, P & pH, Cor, Cond, SDT, Oxid, Dur, $\mathrm{Na}, \mathbf{K}, \mathrm{NH}_{4}, \mathrm{NO}_{3}$ \\
\hline P12 & pH, SDT, Ca, Fe, Na, P & $\begin{array}{l}\text { OD, Turv, Cor, Cond, Oxid, Alc, Dur, Mg, K, } \\
\qquad \mathrm{NH}_{4}, \mathrm{NO}_{3}\end{array}$ \\
\hline
\end{tabular}


Nota: os parâmetros para os quais se registaram maiores diferenças estão escritos a negrito.

Como base nos parâmetros organoléticos, físico-químicos e relativos a substâncias indesejáveis, a água bruta que alimenta as duas ETAs da cidade foi classificada como sendo de classe A2, de acordo com o Decreto-Lei № 236/98, esperando-se assim ser adequado o processo de tratamento convencional (pré-oxidação, coagulação/floculação, decantação, filtração e desinfeção) implementado nestas duas estações. Em relação a estes parâmetros, ambas as ETAs apresentam boa eficiência de remoção de turvação, cor, oxidabilidade, ferro e ortofosfatos, com percentagens de remoção de cerca de $95 \%$ para a turvação e cor. Quanto à contaminação bacteriológica, apesar de não ter sido quantificada, a ausência de bactérias coliformes indica remoção total (100\%), pelo que a ETA nova tem uma eficiência de $100 \%$ na eliminação destas bactérias e a ETA antiga tem uma eficiência mais baixa $(50 \%$ das suas amostras acusaram presença de bactérias coliformes). Relativamente à eficiência do tratamento, a partir dos resultados do presente estudo pode-se dizer que a água à saída da ETA nova obedece aos padrões de potabilidade (apesar do excesso de cloro residual livre e de alumínio), mas à saída da ETA antiga não é recomendável do ponto de vista microbiológico, tornando-se num potencial risco para a saúde dos consumidores.

Em termos físico-químicos, a água da rede pública, na época da chuva, na maioria dos pontos, apresentou valores da turvação e do teor de alumínio acima dos recomendados (4 UNT e $200 \mu \mathrm{g} / \mathrm{L}$, respetivamente). Esta água, do ponto de vista microbiológico, oferece riscos para a saúde por se apresentar contaminada com coliformes em mais do que $50 \%$ das amostras analisadas, particularmente na época da chuva.

De acordo com o Decreto-Lei no 236/98, uma água subterrânea só pode ser utilizada para o consumo humano se for da classe A1, impondo-se o tratamento adequado para as águas desta classe (filtração e desinfeção). Por outro lado, o Decreto-Lei no 306/2007 estabelece os valores paramétricos para água destinada ao consumo humano, independentemente da sua origem. Os resultados do presente estudo mostram que a água dos furos artesianos apresenta contaminação por azoto amoniacal $\left(\mathrm{NH}_{4}\right)$ na época da chuva (exceto no ponto $\mathrm{P} 3$ ) e por microrganismos patogénicos nas duas épocas, não sendo assim adequada para consumo humano sem tratamento. Como mostra a Tabela 4, as águas das cacimbas (pontos P4 a P12) revelam fundamentalmente contaminação por matéria em suspensão, compostos de azoto $\left(\mathrm{NH}_{4}, \mathrm{NO}_{3}\right)$ e fósforo $(\mathrm{P})$ e microrganismos patogénicos, com maior incidência na época da chuva. Assim, as águas de todas as cacimbas estudadas são impróprias para consumo humano sem que seja efetuado um tratamento adequado.

Os resultados do presente estudo apresentados nas Tabelas 5 e 6 mostram que as variações climáticas sazonais afetaram a qualidade da água da rede de abastecimento público e do sistema alternativo. Na época da chuva, em alguns pontos do sistema de abastecimento público, foram registados aumentos significativos de cor, turvação, condutividade, alumínio, dureza, cálcio, ferro, potássio e azoto amoniacal. Em relação à água dos furos e cacimbas, na época da chuva foram registados valores significativamente mais elevados de turvação, condutividade, potássio, dureza, oxidabilidade, azoto amoniacal e nitratos, revelando que a proliferação do uso de fossas negras pela população contribui para piorar a qualidade das águas subterrâneas na época da chuva.

Em relação às estações de tratamento de água é necessário melhorar a eficiência dos processos de coagulação/floculação e desinfeção e operacionalizar o funcionamento dum laboratório de controlo diário da qualidade da água bruta, tratada à saída da ETA e ao longo da rede de distribuição. Em relação à rede de distribuição, é necessário minimizar ou eliminar o risco de ruturas das condutas, por serem pontos de entrada de contaminantes, particularmente na época da chuva, e também para reduzir as perdas de água. No que respeita aos furos e cacimbas, que constituem a principal fonte de água para a população pelo facto das ETAs não produzirem água suficiente, é necessário evitar a sua construção na vizinhança de fossas sépticas, implementar sistemas de tratamento capazes de tornarem potáveis as suas águas e controlar periodicamente a respetiva qualidade.

\section{Conclusão}

A cidade do Uíge é uma referência nacional em termos da predominância de doenças de veiculação hídrica. Neste trabalho foram investigadas três categorias de águas (rede pública, furos artesianos e cacimbas) consumidas maioritariamente pela população da área de estudo, concluindo-se que nenhuma delas oferece garantias de segurança no que respeita à saúde pública devido a contaminação por coliformes fecais. No sistema de abastecimento alternativo (furos e cacimbas), verificou-se um aumento do teor de matéria orgânica na época chuvosa, o que pode dever-se à infiltração de águas pluviais que arrastam muita matéria orgânica; todavia, apesar 
deste aumento, o seu teor não é anormalmente elevado quando comparado com o valor máximo recomendado, mas é um sinal de alerta. Por outro lado, as águas das cacimbas (pontos P4 a P12) são de pior qualidade que as águas dos furos artesianos.

Os resultados microbiológicos das águas do sistema alternativo revelam haver contaminação fecal em quase $100 \%$ das amostras de água das cacimbas e em mais de $80 \%$ das amostras de água dos furos artesianos, tendo-se concluído que existe uma relação entre qualidade da água consumida e a prevalência de doenças de veiculação hídrica predominantes na população. Essas doenças só poderão diminuir com a melhoria da qualidade da água fornecida à população.

Nos casos raros de ausência de contaminação fecal, como acontece na água imediatamente à saída da ETA nova (P5) e no chafariz do Bairro Candome Novo (P13), antes dos reservatórios gravíticos, os teores de cloro livre residual excedem largamente o valor máximo recomendado $(0,6 \mathrm{mg} / \mathrm{L})$, podendo dar origem irritações da pele e dos olhos e a outro tipo de doenças provocadas por compostos, designadamente clorofórmio, resultantes da reação do cloro com a matéria orgânica presente na água. Além disso, no ponto P13, o valor médio de alumínio está ligeiramente acima do valor paramétrico $(200 \mu \mathrm{g} / \mathrm{L})$. Embora este elemento pareça não ter nenhuma função biológica significativa, algumas pessoas manifestam alergia ao alumínio. Na ETA antiga deve dar-se uma atenção especial ao processo de desinfeção, uma vez que a água tratada apresenta valores de cloro residual livre abaixo da gama recomendada $(0,2 \mathrm{a} 0,6 \mathrm{mg} / \mathrm{L})$. Os resultados do presente estudo obrigam-nos a propor algumas medidas de curto prazo para melhorar a qualidade da água consumida pela população do Uíge.

\section{Agradecimentos}

Os autores deste trabalho agradecem os apoios da Direç̧ão Nacional de Águas e do Laboratório da Ambiáfrica em equipamento e testes de campo e nas determinações de parâmetros microbiológicos.

\section{Referências}

Boaventura, R., \& Leitão, A. (2013). Indicadores de qualidade da água. Apontamentos da cadeira de Qualidade de Águas e Águas Residuais. Curso de Mestrado em Engenharia do Ambiente. Faculdade de Engenharia da Universidade Agostinho Neto, Angola.

Decreto-Lei no 236/98, de 1 de Agosto. Diário da República no 176 -1ㅡ Série A. Ministério do Ambiente, Portugal.

Decreto-Lei no 306/2007, de 27 de Agosto. Diário da República no 164 - 1a Série A. Ministério do Ambiente, do Ordenamento do Território e do Desenvolvimento Regional, Portugal.

Decreto Presidencial no 261/11, de 6 de Outubro. Diário da República no 193 - 1ạ Série. Presidente da República, Angola.

DPEAU - Direcção Provincial de Energia e Águas do Uíge. 2013. Plano Director de Abastecimento de Água e Saneamento do Uíge. GPU, Angola.

Eaton, A., Clesceri, L., Rice, E., \& Greenberg, A. (2005). Standard Methods for the Examination of Water and Wastewater. 21th Edition. APHA, Washington, USA.

GPU - Governo Provincial do Uíge. 2012. Perfil da Província do Uíge, Angola.

Index Mundi. (2016). Disponível em http://www.indexmundi.com/angola/

Libânio, M. (2010). Fundamentos de qualidade e tratamento de água. 3ạ ed. revisada e ampliada. Campinas, SP: Átomo.

Manuel, P. (2014). Avaliação do índice de casos por doenças de veiculação hídrica no Hospital Provincial do Uíge. Estudo de caso, Especialização em Engenharia do Ambiente, Faculdade de Engenharia, Universidade Agostinho Neto, Luanda. 
Marquezi, M. (2010). Comparação de metodologias para estimativa do número mais provável (NMP) de coliformes em amostras de água. Dissertação de mestrado, Escola Superior de Agricultura Luiz de Queiroz - Universidade de São Paulo, Piracicaba, Brasil.

Philippi, A. (2005). Saneamento, saúde e ambiente: fundamentos para um desenvolvimento sustentável. Barueri, SP: Manole, Brasil.

Resolução no 10/04, de 11 de Junho. Plano de Acção Estratégico do Sector de Águas para o Período 2004-2016. Conselho de Ministros, Angola.

Sanchez, P. (1996). Actualização em técnicas para o controlo microbiológico de águas minerais. Universidade Mackenzie. São Paulo, Brasil.

Shubo, T. (2003). Sustentabilidade do abastecimento e da qualidade da água potável urbana. Dissertação de mestrado, Escola Nacional de Saúde Pública da Fundação Osvaldo Cruz. Rio de Janeiro, Brasil.

SPINE. (2015). Resultados provisórios do Censo Geral de 2014. Angola.

WHO - World Health Organization. (1996). Guidelines for drinking water quality. 2.ed. Genebra: WHO.

WHO - World Health Organization. (2005). The treatment of diarrhoea: a manual for physicians and other senior health workers. 4a Ver., p.44. Retrieved from http://apps.who.int/iris/bitstream/10665/43209/1/9241593180.pdf.

WHO - World Health Organization (2006). Guidelines for drinking water quality. 3rd ed. Vol.1. Recommendations.

\section{Sobre os Autores}

Paulo Manuel (MsC) é docente do Departamento de Ciências Exactas/Secção de Química do Instituto Superior de Ciências da Educação (ISCED) do Uíge. Mestre em Engenharia do Ambiente pela Faculdade de Engenharia da Universidade Agostinho Neto.

Anabela A. Leitão (PhD) é Directora do LESRA - Laboratório de Engenharia da Separação, Reacção Química e Ambiente da Universidade Agostinho Neto, Luanda, Angola. Professora Titular da Faculdade de Engenharia da Universidade Agostinho Neto, Luanda, Angola. É Doutorada em Engenharia Química pela Universidade do Porto.

Rui A.R. Boaventura (PhD) é investigador principal (aposentado) da Faculdade de Engenharia da Universidade do Porto, Portugal. Membro integrado do Laboratório Associado LSRE-LCM, Laboratório de Processos de Separação e Reação-Laboratorio de Catálise e Materiais. É Doutorado em Engenharia Química pela Universidade do Porto. 